\title{
Temperature Uniformity of Heated Mold Plate by Oscillating Heat Pipe
}

\author{
Patrapon Kamonpet $^{1, a}$, Phrut Sakulchangsatjathai ${ }^{1}$ \\ ${ }^{1}$ Department of Mechanical Engineering, Faculty of Engineering, Chiang Mai University, Thailand
}

\begin{abstract}
Uniformity of the temperature in the mold plate is of paramount important since it will affect the dimensional stability of the part produced. To provide uniform temperature to the metal plate, many factors need to be considered such as choice of heating technology, uniformity of a heat source, a type of control, etc. This paper aims to study the temperature uniformity of metal plate using closed-loop oscillating heat pipe (CLOHP) as a heat transfer device. The metal plates which were P-20 with the size of $306 \times 130 \mathrm{~mm}^{2}$ were used. Metal plate was gouged to a depth of $3 \mathrm{~mm}$ for installing the CLOHP. Distances from the heating device to the metal plate surface were 5 and 10 $\mathrm{mm}$. The surface temperatures of the metal plate were controlled at $80,90,100,110,120$, and $130^{\circ} \mathrm{C}$. Sixteen pointa of temperature were recorded. The results were then compared to those using the heat source as the cartridge heater arranged in the similar way with the same heating capacity. Once the system entered the steady state, it was found that the temperature distribution of metal plate using the CLOHP has a deviation in the range of $\pm 1.00^{\circ} \mathrm{C}$ and \pm $0.94^{\circ} \mathrm{C}$ at the CLOHP depth of $5 \mathrm{~mm}$. and $10 \mathrm{~mm}$., respectively. While those of using cartridge heater deviated in the range of $\pm 1.35^{\circ} \mathrm{C}$ and $\pm 1.16^{\circ} \mathrm{C}$. Compare to the recommended value from the ASTM Standard that the mold surface temperature need to be in the range of $\pm 2.0^{\circ} \mathrm{C}$, the CLOHP shows the very promising results.
\end{abstract}

\section{Introduction}

Heating of the cavity steel mold plates during the molding process, especially in the processing of plastic parts, are important to part quality and production time. Heating of the cavity mold plates, especially a bit higher than the glass transition temperature, ensures that the parts could be optimally filled with good aesthetic surface quality. The problems such as weld line, jetting, fiber mark, and all other flow line traces can be eliminated, as such secondary operations i.e., sanding, coating, or coloring, are no longer needed. This ensures increase in production rate. Heating of the cavity molding plates ensures longer flow length of plastic melt during flow in the cavity, as a result, thin-wall parts can be produced with more intricate detail and less molded in stress. Heating process usually is an auxiliary unit equipped to conventional molding machines. There have been many researches, during the past 20 years; investigate the technologies of the heating process. To date, the heating technologies can be classified into four groups which are conduction heating, convection heating, induction heating, and radiation heating [1]. Although these heating technologies can provide satisfactory heating rate, there is limited assurance that the temperature will be uniform. It is reported that the temperature between cavity to cavity in the molding of rubber with cartridge heater can be varied as much as $4.7{ }^{\circ} \mathrm{C}$ which caused flash or distortion [2]. Athanasopoulos, N, et al. [3], reported that by using carbon fiber as heating element in the mold cavity, the minimum temperature tolerance achieved was $\pm 2.6{ }^{\circ} \mathrm{C}$.

\footnotetext{
a Corresponding author: author@e-mail.org
}

While Sung, Y. T. et al., [4] found that by using inductive heating, the standard deviation of temperature can be ranging from $1.44{ }^{\circ} \mathrm{C}$ to $25.82{ }^{\circ} \mathrm{C}$. Standard procedure recommended that to get good parts, the mold surface temperature need to be in the range of $\pm 2.0{ }^{\circ} \mathrm{C}[2,5]$. Uniformity of the temperature in the molding plate is of paramount important since it will affect the dimensional stability of the part produced. Orientation and differential cooling rate are the main factors that affect in differential part shrinkage resulting in part warpage. To provide uniform temperature to the metal plate, the heat source must also be placed in a uniform manner. It is obvious that all of the above methods require primary heat source to heat up the plate. There is no doubt that the temperature in the area that closed to the heat source will be higher than those far away from the heat source. Basic rule recommended that to achieve uniform temperature, the distance between adjacent heating passages should be around 2 to 2.5 times of the diameter of the passage and the distance from the heating surface should be around 1 to 1.5 times [6].

Heat Pipe is a heat transfer device which can provide excellent heat transfer rate. It is a vacuum closed pipe containing working fluid which can transfer heat from one hot end to another cold end by evaporation and condensation mechanism inside the pipe as shown in Fig 1. Heat pipe has been continuously used in many molding application due to its high in heat transfer performance and low in maintenance cost as there is no moving parts [7]. However, the usage has been mainly limited to cooling of the mold in a very specific area where high 
heat transfer rate is required. To date, the heat pipe technology is advanced and there are many new types of heat pipe such as micro heat pipe, oscillating heat pipe, and micro oscillating heat pipe. Oscillating heat pipe, as the name implied, works by oscillating mechanism of vapor bubbles and liquid plug of the working fluid inside the meandering pipe [8], as shown in Fig 2. Oscillating heat pipe has been developed around 20 years ago. So far, it has been applied to many applications including space radiator and cooling in the miniature electronic devices [9], as shown in Fig.3a. and Fig.3b. Since the basic characteristics of oscillating heat pipe is the meandering turns of a lengthy small tube placed in an equally spacewise as shown in Fig 2 and Fig.3, it can then be placed in between the mold plate to transfer heat in the cavity with a more uniform temperature distribution. Moreover, the tube can be bent in any required shape. This paper investigates the temperature uniformity of the metal plate when oscillation heat pipe is applied as a heat transfer device.

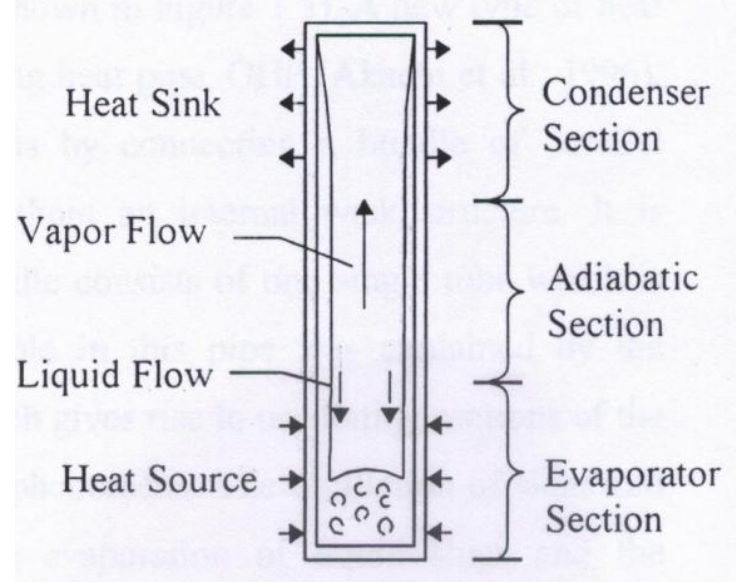

Fig. 1. Heat Pipe

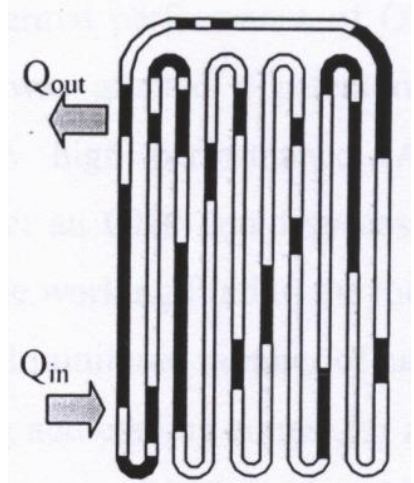

Fig.2. Oscillating Heat Pipe

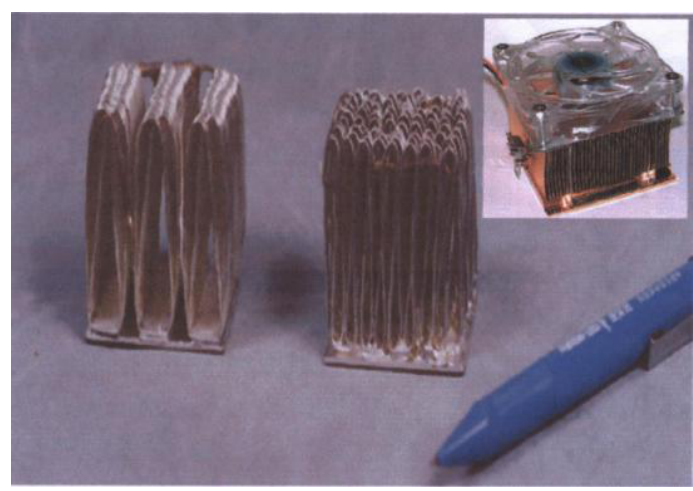

Fig. 3a. Oscillating Heat Pipe Used to Cool Miniature Electronic Devices [9]

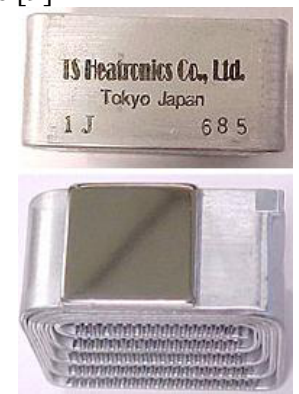

Fig. 3b. Oscillating Heat Pipe Used to Cool Miniature Electronic Devices [9]

\section{Experimental Apparatus and Method}

\subsection{Experimental Setup}

Of the four types of heating technologies mentioned previously, convection with steam heating and conduction with electric heating are found to be vastly feasible. It is, therefore, the aims of this study, to compare the uniformity of temperature that convective heating, with CLOHP, and that conductive heating, with cartridge heater, can provide [2]. P-20 metal plate with the size of $306 \times 130 \mathrm{~mm}^{2}$ was used as a heat sink, while 2 types of heat source were used which are oscillating heat pipe and cartridge rod heater. The setups were as shown in Fig. 4a. and Fig. 4b. 12-turn of oscillating heat pipe with the internal tube diameter of $2 \mathrm{~mm}$. was used. The working fluid was water with the filling ratio of $50 \%$ of the total inside volume. The evaporator length was 50 $\mathrm{mm}$. and the condenser length was $150 \mathrm{~mm}$. An electric strip heater of 300 watts was used as a heat source for oscillating heat pipe [10]. Metal plate was gouged to a depth of $3 \mathrm{~mm}$ for installing the oscillating heat pipe. For comparison of the result, 12 cartridge rod heaters with 6 $\mathrm{mm}$ in diameter, each of $25 \mathrm{~W}$ were also setup and studied. Distances from the heating device to the metal plate surface were 5 and $10 \mathrm{~mm}$. The surface temperatures of the metal plate were controlled at $80,90,100,110,120$, and $130^{\circ} \mathrm{C}$. This temperature range is consisted with melt temperature of Polyethylene, $80^{\circ} \mathrm{C}$ to $120^{\circ} \mathrm{C}$, which is the most widely used plastics in the world [11]. Sixteen Thermocouples were installed on the metal surface to record the temperature distribution of the surface. Fig.5a and Fig. 5b. show 16-location of the thermocouples. 


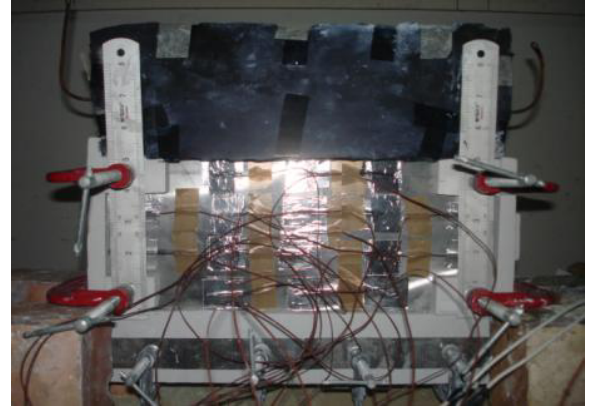

Fig. 4a. Experimental setup for CLOHP

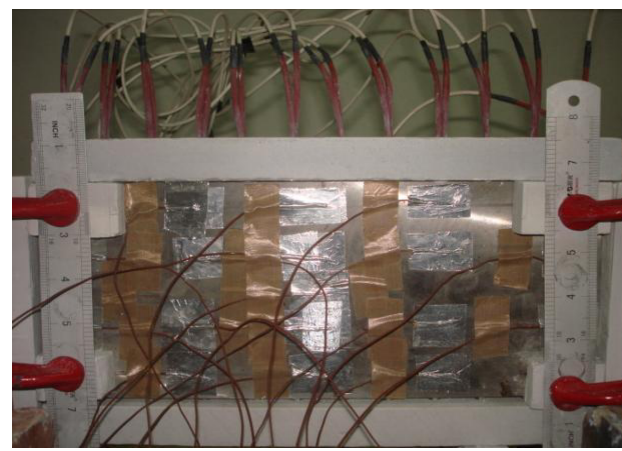

Fig. 4b. Experimental setup for Cartridge Heater

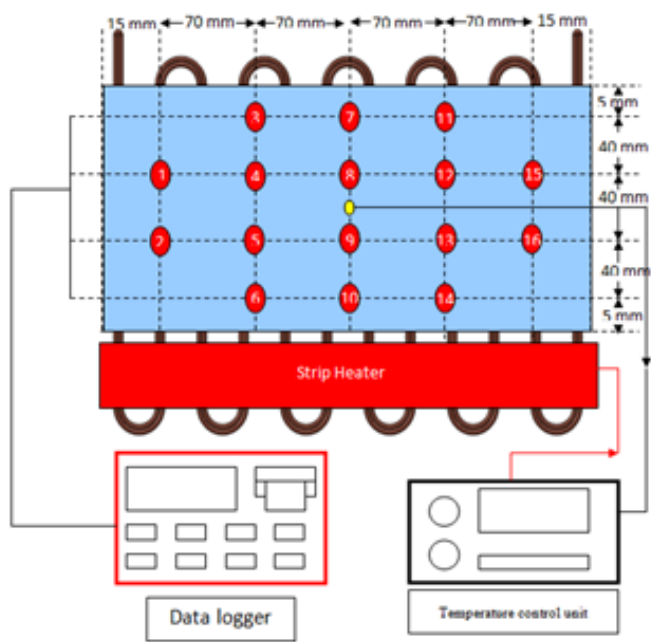

Fig.5a. 16-location of thermocouple for CLOHP

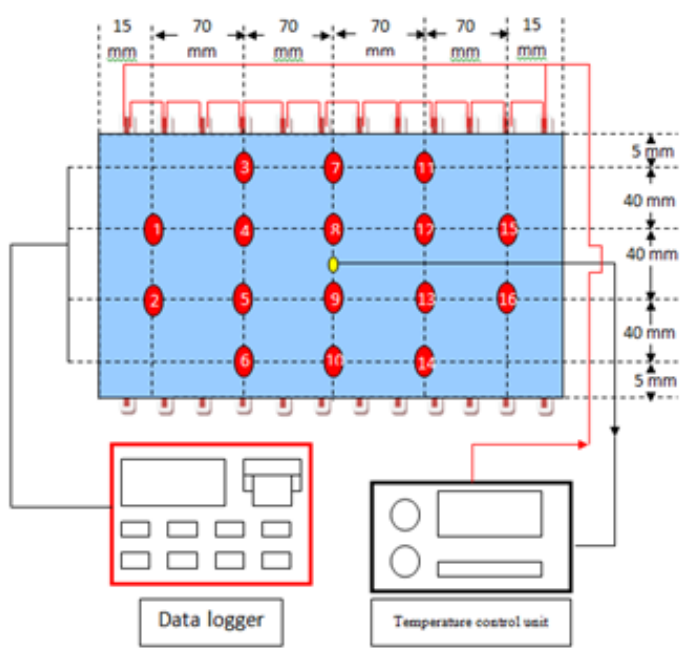

Fig.5b. 16-location of thermocouple for Cartridge Heater

\subsection{Experimental Method and Analysis.}

Once the heater was on, the surface temperature of the metal plate equipped with CLOHP heat source was recorded until it reached the set point and was stabilized, the data of each location, then, was recorded for duration of 60 minutes. The procedure was replicated for another 2 times. The whole procedure was repeated as the set temperature was increased to the next value. The same procedure was also followed with the cartridge rod heater as a heat source. The temperature uniformity is then reported by Eq. (1)

$$
\mathrm{STD}=\sqrt{\frac{\sum_{\mathrm{i}=1}^{\mathrm{N}}\left(\mathrm{X}_{\mathrm{i}}-\overline{\mathrm{X}}\right)^{2}}{\mathrm{~N}}} .
$$

Where STD is the standard deviation of the samplings from each set surface temperature

$\mathrm{X}$ is measured temperature

$\mathrm{X}$ is set surface temperature

$\mathrm{N}$ is sampling size which is 48 data points

However, when standard deviation (SD) at each location

is concerned, $\mathrm{X}$ is the average measured surface temperature and to differentiate this value from the STD, as reported in Table 3, the SD is used.

\section{Results and Discussion}

Fig. 6 compares the temperature uniformity of the 8-mmthick metal plate using CLOHP and HR as a heat source placed $5 \mathrm{~mm}$ under the metal surface at the set temperature of $80{ }^{\circ} \mathrm{C}$ and $130{ }^{\circ} \mathrm{C}$. The group of number 1 to 16 on the chart shows the locations of the thermocouple while another group on the chart shows the temperature at each location. Location 15, 16, 1, and 2 are the location at the boundary of the heat source and the left and right edges of the plate, as mentioned in Fig.5. The temperatures at these locations show fluctuation due to boundary effect. As shown in Fig.6, the temperatures at the location 3 to 14 of the plate heated by both heat sources show cyclic pattern i.e., for HR, the temperatures were repeatedly low at location 3 and high at location 4 to 6 and then low at location 7 and high again at location 8 to 10 and low again at location 11 , and so on. This is because the nature of the heater. The end of the heater that connected to electrical wire, which are locations number 3, 7, 11, as per Fig.5, will always shows lower temperature than the other end. Since the 12-heater was connected in series, then the cyclic pattern is unavoidable presented. For CLOHP, although it is less obvious, the cyclic pattern is also shown. This is because the working fluid inside the pipe must flow along the pipe which is in U-shape, the evaporator section of the heat pipe is in the lower side and the condensing section is in the upper side, the temperature closed to the evaporator section will always be higher than those near the condensing section. This cyclic pattern is clearly seen at the lower set temperature, i.e. $80{ }^{\circ} \mathrm{C}$. However, when the temperature 
increases to $130{ }^{\circ} \mathrm{C}$, the temperature distribution of metal plate with CLOHP was more uniform especially at the locations of 3 to 14, as shown in Fig 6. The temperature distribution of the metal plate with HR shows the cyclic pattern which swings wider at high set surface temperature than that at lower set temperature.

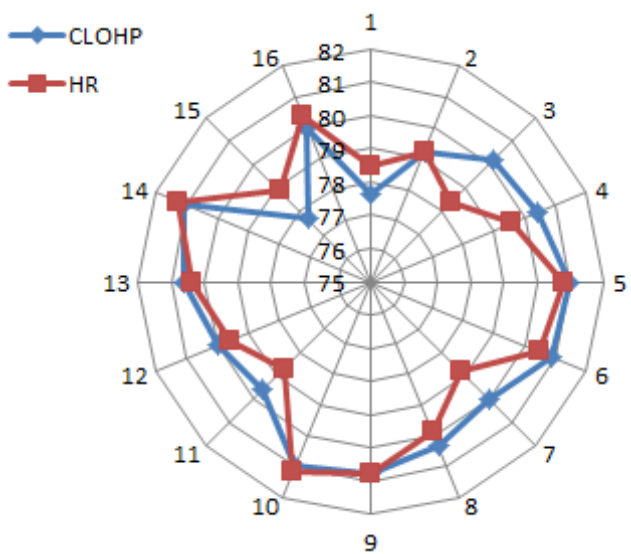

(a) Set Temperature of $80{ }^{\circ} \mathrm{C}$

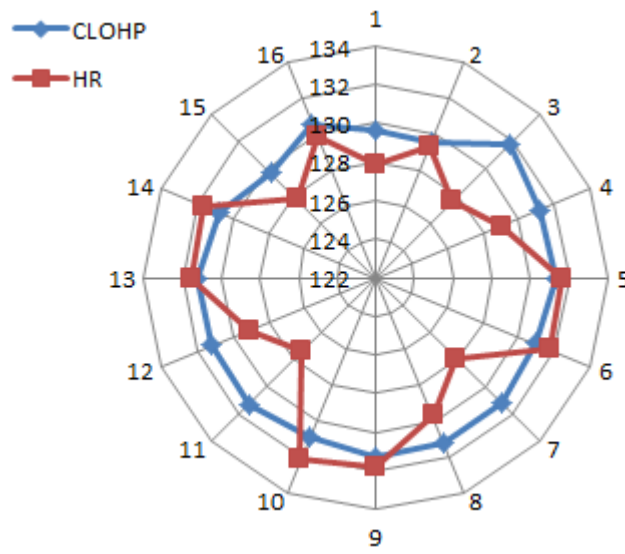

(b) Set Temperature of $130{ }^{\circ} \mathrm{C}$

Fig. 6 Surface Temperature at each location the 8-mm-thick metal plate using CLOHP and HR as a heat source placed $5 \mathrm{~mm}$ under the metal surface at the set temperature of 80 and $130{ }^{\circ} \mathrm{C}$.

The temperature distribution can be compared as well by the STDs values. As mention previously that STDs implies the degree Celsius of the deviation of temperature at all location from the set point. The result is clearly seen in Table 1 which shows the values of STDs for different set temperatures of CLOHP and HR as heat sources for the metal plate. It is clearly seen that for the case of placing the heating device at a distances of $5 \mathrm{~mm}$ from the metal plate surface, at $80{ }^{\circ} \mathrm{C}$ of the set surface temperature, HR yields better result than CLOHP since the value of STDs are lower. However, when the temperature increased, the values of STDs of CLOHP are better than those of HR. From Table 1, it is found that CLOHP yields lower STDs than HR at the set temperature of $90{ }^{\circ} \mathrm{C}$ to $130{ }^{\circ} \mathrm{C}$, which mean the CLOHP gives more uniform temperature distribution. Nevertheless, when the end effect of the heat pipe was neglected, considering only location 3 to 14 , it is found that CLOHP yields lower STDs than HR at every set temperature, $80{ }^{\circ} \mathrm{C}$ to $130{ }^{\circ} \mathrm{C}$, as shown in Table 2 . The results for the case of $10-\mathrm{mm}$ depth, also show the same trend.

When considering the preciseness of the temperature at each location, the values of SDs at each location are considered. Table 3 shows the SDs values at location 8 which is in middle of the plate. The SD values of set surface temperature at location 8 will be used as a representative for the data at other set temperature as well since they all show the same trends. As can be seen CLOHP gives lower values of SDs as the set temperature increased from $80{ }^{\circ} \mathrm{C}$ to $130{ }^{\circ} \mathrm{C}$, which implied that the precision is improved as the temperature increases. In the contrary, the SDs results of the HR shows the opposite direction. In conclusion, it can be stated that using CLOHP as a heat transfer device yields better distribution as well as preciseness of the metal plate surface temperature than using HR.

Table 1 Standard deviation (STDs) of the surface temperature for 16-location Using CLOHP and HR as heat sources

\begin{tabular}{|c|c|c|c|c|}
\hline \multirow{2}{*}{$\begin{array}{c}\text { Temp. } \\
\left({ }^{\mathrm{O}} \mathrm{C}\right)\end{array}$} & \multicolumn{2}{|c|}{ STDs $\left({ }^{\circ} \mathrm{C}\right)$ for CLOHP } & \multicolumn{2}{c|}{ STDs $\left({ }^{\circ} \mathrm{C}\right)$ for HR } \\
\cline { 2 - 5 } depth & $\begin{array}{c}10-\mathrm{mm} \\
\text { depth }\end{array}$ & $\begin{array}{c}\text { 5-mm } \\
\text { depth } \\
\pm 1.033\end{array}$ & $\begin{array}{c}10-\mathrm{mm} \\
\text { depth }\end{array}$ \\
\hline 80 & \pm 0.631 & \pm 0.971 & \pm 0.681 \\
\hline 90 & \pm 0.978 & \pm 0.890 & \pm 1.100 & \pm 0.790 \\
\hline 100 & \pm 0.999 & \pm 0.861 & \pm 1.292 & \pm 0.905 \\
\hline 110 & \pm 0.973 & \pm 1.072 & \pm 1.444 & \pm 1.000 \\
\hline 120 & \pm 0.959 & \pm 0.913 & \pm 1.585 & \pm 1.140 \\
\hline 130 & \pm 1.079 & \pm 0.776 & \pm 1.684 & \pm 1.314 \\
\hline
\end{tabular}

Table 2 Standard deviation (STDs) of the surface temperature for locations 3 to 14 Using CLOHP and HR as heat sources

\begin{tabular}{|c|c|c|c|c|}
\hline \multirow{2}{*}{$\begin{array}{l}\text { Temp. } \\
\left({ }^{\mathrm{O}} \mathrm{C}\right)\end{array}$} & \multicolumn{2}{|c|}{ STDs $\left({ }^{\circ} \mathrm{C}\right)$ for CLOHP } & \multicolumn{2}{|c|}{ STDs $\left({ }^{\circ} \mathrm{C}\right)$ for $\mathrm{HR}$} \\
\hline & $\begin{array}{l}\text { 5-mm } \\
\text { depth }\end{array}$ & $\begin{array}{c}10-\mathrm{mm} \\
\text { depth }\end{array}$ & $\begin{array}{l}\text { 5-mm } \\
\text { depth }\end{array}$ & $\begin{array}{l}\text { 10-mm } \\
\text { depth }\end{array}$ \\
\hline 80 & \pm 0.678 & \pm 0.514 & \pm 0.958 & \pm 0.705 \\
\hline 90 & \pm 0.628 & \pm 0.349 & \pm 1.133 & \pm 0.806 \\
\hline 100 & \pm 0.643 & \pm 0.266 & \pm 1.333 & \pm 0.902 \\
\hline 110 & \pm 0.871 & \pm 0.291 & \pm 1.491 & \pm 1.005 \\
\hline 120 & \pm 0.981 & \pm 0.273 & \pm 1.623 & \pm 1.139 \\
\hline 130 & \pm 1.222 & \pm 0.303 & \pm 1.727 & \pm 1.315 \\
\hline
\end{tabular}

Table 3 Standard deviation (SDs) of the surface temperature for locations 8Using CLOHP and HR as heat sources

\begin{tabular}{|c|c|c|c|c|}
\hline $\begin{array}{c}\text { Temp. } \\
\left({ }^{\mathrm{O}} \mathrm{C}\right)\end{array}$ & \multicolumn{2}{|c|}{$\mathrm{SD}\left({ }^{\circ} \mathrm{C}\right)$ of CLOHP } & \multicolumn{2}{c|}{$\mathrm{SD}\left({ }^{\circ} \mathrm{C}\right)$ of HR } \\
\cline { 2 - 5 } & $\begin{array}{c}5-\mathrm{mm} \\
\text { depth }\end{array}$ & $\begin{array}{c}10-\mathrm{mm} \\
\text { depth }\end{array}$ & $\begin{array}{c}\text { 5-mm } \\
\text { depth }\end{array}$ & $\begin{array}{c}\text { 10-mm } \\
\text { depth }\end{array}$ \\
\hline 80 & \pm 0.067 & \pm 0.056 & \pm 0.044 & \pm 0.037 \\
\hline 90 & \pm 0.051 & \pm 0.050 & \pm 0.051 & \pm 0.045 \\
\hline
\end{tabular}




\begin{tabular}{|c|c|c|c|c|}
\hline 100 & \pm 0.047 & \pm 0.031 & \pm 0.045 & \pm 0.053 \\
\hline 110 & \pm 0.039 & \pm 0.040 & \pm 0.053 & \pm 0.068 \\
\hline 120 & \pm 0.034 & \pm 0.036 & \pm 0.056 & \pm 0.061 \\
\hline 130 & \pm 0.042 & \pm 0.041 & \pm 0.063 & \pm 0.057 \\
\hline
\end{tabular}

Fig. 7 compares the STDs values of surface temperature at different depth from the metal surface. It is apparent that CLOHP offers better surface temperature distribution than HR whether the heating device is installed at $5 \mathrm{~mm}$ or $10 \mathrm{~mm}$. Increasing the depth of installing the heating device improves the temperature distribution of the plate. For CLOHP, there is little improvement and it is statistically significant. However, for HR the improvement is quite apparent but it is not statistically significant at $95 \%$ confidence limit.

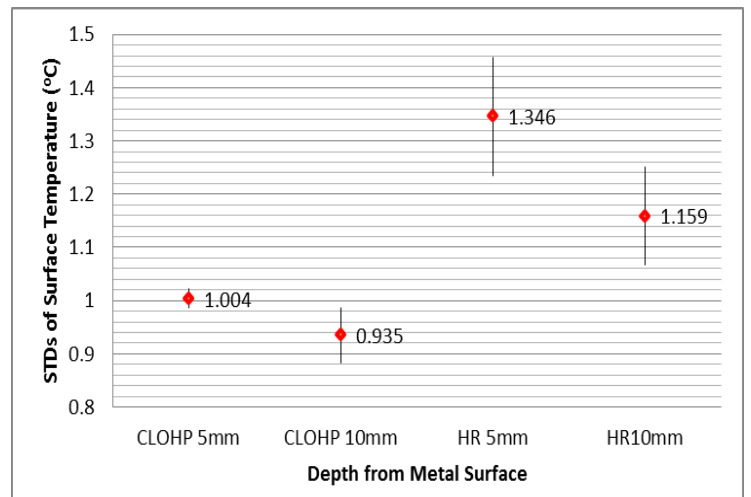

Fig. 7. STDs values of surface temperature at different depth from the metal surface.

\section{Summary}

The temperature distribution of metal plate using closed loop oscillating heat pipe (CLOHP) as the heat transfer device was more uniform than that using cartridge rod heater (HR). The STDs which is the degree Celsius of the deviation of temperature at all location from the set point of CLOHP at $5 \mathrm{~mm}$ and $10 \mathrm{~mm}$ are $1.004^{\circ} \mathrm{C}$ and $0.935^{\circ} \mathrm{C}$ while those of HR are $1.346{ }^{\circ} \mathrm{C}$ and $1.159^{\circ} \mathrm{C}$. When considering the preciseness of the temperature at each location, it is found that CLOHP yields better preciseness in surface temperature than HR.

\section{References}

1. K. Mikell, Rapid Mold Heating, Cooling Technology on Cutting Edge, Plastics Machinery Magazine, October (2014)

2. K. Mikell, Thermoset Molder Closes the Loops on Mold Temperature Control, Plastics Technology, October (2008)

3. N. Athanasopoulos, G. Koutsoukis, D. Vlachos, and V. Kostopoulos, Temperature Uniformity Analysis and Development of Open Lightweight Composite Molds Using Carbon Fibers as Heating Elements, Composite: Part B. 50, 279-289 (2013).
4. Sung, Y, T., Lin, Y. N., Hwang, S. J., Lee, H. H., and Huang, D. Y., Design of Induction Heating Module for Uniform Cavity Surface Heating, ANTEC, (2011)

5. ASTM D957-06, Standard Practice for Determining Surface Temperature of Molds for Plastics, American Society of Testing and Materials, (2006)

6. G. Wang, G. Zhao, H. Li, and Y. Guan, Thermal Response Simulation and Mold Structure Optimization for Rapid Heat Cycle Molding Processes with Steam Heating and Electric Heating, Material and Design 31, 382-395 (2010)

7. Information http://www.thermacore.com/documents/moldcooling-solutions.pdf.

8. P. Charoensawan, P. Terdtoon, P. Tantakom, P. Ingsuwan, and M. Groll, Effect of Inclination Angles, Filling Ratio and Total Lengths of Heat Transfer Characteristic of A Closed-Loop Oscillating Heat Pipe, Procs. Of the $7^{\text {th }}$ International Heat Pipe Symposium, Jeju, Korea, 360-367, (2003)

9. Capillary Tube Heat Pipe and Temperature Controlling Apparatus, TS Heatronics Co., Ltd., U.S. Patent 6889753. (2005)

10. S. Khandekar, P. Charoensawan, M. Groll, and P. Terdtoon, Closed-Loop Pulsating Heat Pipe Part B: Visualization \& Semi-Empirical Modeling. Applied Thermal Engineering. 23, 2021-2033 (2003)

11. Information on http://www.remichem.com/polyethylene.html 